\title{
Strategy for a Fast and Simple Method for Trace Determination of Senecionine and Senecionine N-Oxide in Honey Using LVI in HPLC-MS/MS
}

\author{
Lizandra Czermainski Bretanha, Marcel Piovezan, Alysson Fernandez Vasques Sako, \\ Moacir Geraldo Pizzolatti, Gustavo Amadeu Micke* \\ Departamento de Química, Universidade Federal de Santa Catarina, Florianópolis, Brazil \\ Email: "gustavo.micke@ufsc.br
}

Received 20 May 2014; revised 3 July 2014; accepted 16 July 2014

Copyright (C) 2014 by authors and Scientific Research Publishing Inc.

This work is licensed under the Creative Commons Attribution International License (CC BY).

http://creativecommons.org/licenses/by/4.0/

c) (i) Open Access

\section{Abstract}

The aims of this study were to develop an HPLC-MS/MS method for the trace determination of senecionine (SEN) and senecionine $\mathrm{N}$-oxide (SENNOX) in honey samples with simple dilution and to optimize the strategy for large volume injection (LVI). In the method development, the quantity of sugar, injection volume and sample $\mathrm{pH}$ were optimized to increase the efficiency and the retention factor of the analytes. Figures of merit of the proposed method include: good linearity $\left(R^{2}>0.99\right)$, limits of detection of 57 and $59 \mathrm{ng} \cdot \mathrm{kg}^{-1}$ for SEN and SENNOX, respectively, and recovery in the range of $83.4 \%-123 \%$. The values for the instrumental precision in relation to the retention time and peak area were $0.65 \%$ and $7.1 \%$, respectively, and for the intra-day precision they were greater than $0.95 \%$ and $9.7 \%$ for SEN and SENNOX, respectively. The LVI-HPLC-MS/MS procedure developed was applied to honey samples prepared by simple dilution with deionized water (1:8 $\mathrm{w} / \mathrm{w}$ ) and the $\mathrm{pH}$ was adjusted to 9.5 with $\mathrm{NH}_{4} \mathrm{OH}$. The sample volume injected was $100 \mu \mathrm{L}$; concentrations in natural and industrialized honey were $<$ LOQ $-1071.3 \mu \mathrm{g} \cdot \mathrm{kg}^{-1}$ for SEN and $<\mathrm{LOD}$ $16.9 \mu \mathrm{g} \cdot \mathrm{kg}^{-1}$ for SENNOX.

\section{Keywords}

Large Volume Injection, HPLC-MS/MS, Honey, Senecionine, Senecionine N-Oxide

\footnotetext{
${ }^{*}$ Corresponding author.
} 


\section{Introduction}

Pyrrolizidine alkaloids (PAs) are toxic compounds mainly synthesized for plant defense and they are probably the most widely distributed natural toxins that affect plants and animals, including humans [1] [2]. The highest concentrations of toxins are usually present in the seeds and flowers of plants [3]. PAs can be metabolized by the liver to generate toxic reactive intermediates called "reactive pyrroles". These compounds have high affinity with the bases of DNA and also with amino acids and proteins [4] and they present high toxicity and genotoxicity.

In humans, PA poisoning can be fatal and is associated with acute hepatic veno-occlusive disease (DOVH) [5] while a chronic or subacute onset may lead to liver cirrhosis. The EFSA (European Food Safety Authority) panel on contaminants in the food chain (CONTAM panel) [6] has concluded that 1,2-unsaturated PAs can act as carcinogens in humans, and thus their consumption in plant-based foods needs to be avoided.

Since the 1950s, reports have been published on the potential toxicity of PAs [7] [8]. Numerous cases of human poisoning after the consumption of the food contaminated with seeds or herbs containing PAs have been reported around the world [7] [9]-[12]. In November 2011, it was determined that the limit for the consumption of these substances in herbal products should not exceed $1 \mu \mathrm{g}$ /day, although for products produced by bees (honey, propolis, royal jelly) these limits have yet to be established [13].

Honey is considered to be a natural healthy product. However, to date little is known regarding the acceptable limits for alkaloids in honey, despite these compounds being considered toxic and present in almost every type of honey found on the market [14]. Consequently, a wide variety of extraction and concentration procedures, as well as methods of analysis, has been developed over the years for the determination of pyrrolizidine alkaloids in food products [13].

In general, PAs are determined by chromatograph techniques using GC-MS and LC-MS due to their sensitivity and specificity [15]-[20]. However, methods using GC-MS are not very suitable for the determination of pyrrolizidine alkaloids $\mathrm{N}$-oxide due to the thermal instability of these molecules which means that a derivatization procedure is required.

The classic methods for sample clean-up involve dissolving the extract in acidulated water with $\mathrm{H}_{2} \mathrm{SO}_{4}$ or $\mathrm{HCl}_{\text {, }}$ and subsequent washing with organic solvent to remove the less polar material. Common procedures are based on SPE with the use of a commercially available column [21]-[23]. In SPE, the QuEChERS sample preparation method has been used for the analysis of honey samples using GC-MS and HPLC-MS [13]. These two methods were compared and proved to be time-consuming, requiring 10 and $3 \mathrm{~h}$, respectively, for complete analysis.

To increase the sensitivity of the HPLC method, the LVI (Large Volume Injection) procedure can be used with or without modification of the equipment hardware. In LVI-HPLC, different strategies can be used to allow a 10-fold increase in the sample volume injected, and increase the retention of the analyte in the column, using dilution of the mobile phase with water or immiscible solvents [24] or sample pH manipulation. Many LVIHPLC methods have been applied to determine illicit drugs in water [25], nitrophenols [26] and fluoro chemical products [27]. In this context, the aim of this study was to develop a fast and efficient methodology using LVI-HPLC-MS/MS with direct injection of the sample for the determination SEN and SENNOX in honey obtained from commercial sources and directly from beekeepers.

\section{Materials and Methods}

The LC-MS/MS was conducted on a high performance liquid chromatography (HPLC) instrument (Agilent Technologies 1200-Germany). For the separation, a Synergi reverse phase chromatograph (150 mm, 2 mm ID, $4 \mu \mathrm{m}$ particle size) was used and the solvent compositions were $\mathrm{A}\left(\mathrm{H}_{2} \mathrm{O}+0.1 \%\right.$ formic acid) and $\mathrm{B}$ (95:5 $\mathrm{MeOH} / \mathrm{H}_{2} \mathrm{O}+0.1 \%$ formic acid). The runs were performed using the following gradient program: 8 - 0 min $80 \%$ solvent A (pre-run; isocratic mode); 0 - 1 min $80 \%$ solvent A (isocratic mode); 1 - 5 min 5\% solvent A (gradient mode); and 5 - 15 min 5\% solvent A (isocratic mode). The flow rate was $0.2 \mathrm{~mL} / \mathrm{min}$ the injected volume was $100 \mu \mathrm{L}$ and the column temperature was $30^{\circ} \mathrm{C}$. The LC-MS system consisted of a hybrid triple quadrupole/linear ion trap mass spectrometer (QTrap 3200, Applied Biosystems/MDS Sciex, Concord, Canada) with an additional valve located after the column. The MS was adjusted in negative and positive modes with the infusion of a polypropylene glycol solution. The experiments were performance using a TurboIonSpray ${ }^{\mathrm{TM}}$ source (electrospray-ESI) in positive ion mode. The capillary needle was maintained at $5500 \mathrm{~V}$. The MS/MS parameters were: curtain gas $10 \mathrm{psi}$; temperature $400^{\circ} \mathrm{C}$; gas 1.45 psi; gas $2.45 \mathrm{psi}$; and CAD gas medium. Other parameters related to the collision energy are given in Figure 1. To control the LC-MS system and for the data analysis the 


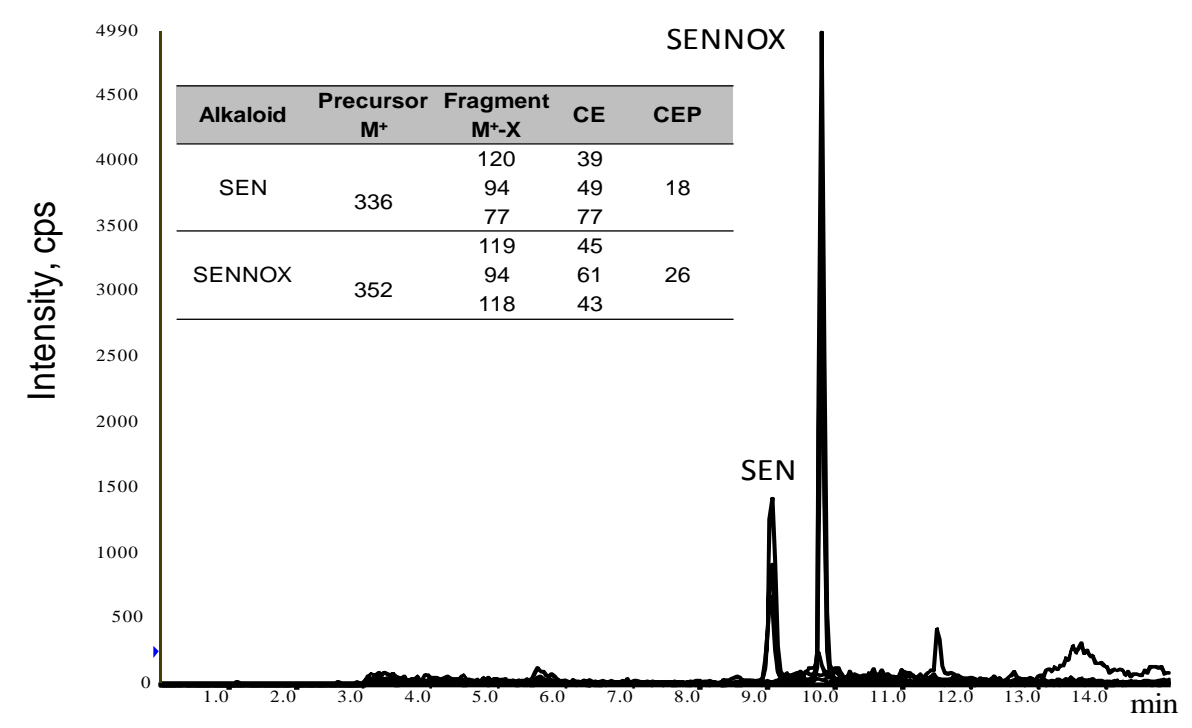

Figure 1. Profile of chromatogram for Sample E in Table 1. Other MS/MS parameters were DP 61, EP 4 and CXP 4.

Analyst 1.5.1 software program was used.

The alkaloid compounds were monitored and quantified using Multiple Reaction Monitoring (MRM). The optimization of the mass spectrometer was performed by direct infusion of the analytes in aqueous solution. To protect the capillary source against caramelization of the sugar present in the sample, which runs through the column at $0-3 \mathrm{~min}$, this is discharged through a valve added after the column.

\subsection{Reagents and Solutions}

All reagents used in the experiments were analytical grade. The ammonium hydroxide $\left(\mathrm{NH}_{4} \mathrm{OH}\right)$ and formic acid were purchased from Sigma, the methanol (MeOH) was acquired from Tedia Brazil (Rio de Janeiro, Brazil) and the glucose and fructose were supplied by Sigma-Aldrich. For the preparation of the samples and mobile phase deionized water was used (Milli-Q deionizer, Millipore, Bedford, MA, USA). The stock standard solutions of senecionine and senecionine $\mathrm{N}$-oxide alkaloids $\left(1000 \mathrm{mg} \cdot \mathrm{L}^{-1}\right)$ were prepared in methanol. The standards used were obtained from Prof. Dr Moacir Pizzolatti’s laboratory (UFSC, SC, Brazil).

\subsection{Calibration Curves and Sample Preparation}

Some of the samples of commercial floral honey were acquired in a local market and others were obtained directly from the producers (beekeepers) in different towns of Santa Catarina state in Brazil. The samples were prepared by placing approximately $1.0 \mathrm{~g}$ of honey in a flask followed by dilution with water to obtain a final mass of $8.0 \mathrm{~g}$. After complete homogenization the sample $\mathrm{pH}$ was adjusted to 9.5 with $\mathrm{NH}_{4} \mathrm{OH}$ and analyzed using the LC-MS/MS system. The optimization of the separation procedure was performed with a stock aqueous solution comprised of 35\% glucose and 35\% fructose (total sugar 70\%), in order to mimic the honey matrix, with the addition of SEN and SENNOX to give a final concentration of $50 \mu \mathrm{g} \cdot \mathrm{kg}^{-1}$. The calibration curves were performed with a stock solution containing $8 \%$ total sugar and constructed in the range concentration of 200 $2000 \mathrm{ng} \cdot \mathrm{L}^{-1}$ to SEN and SENNOX.

\section{Results and Discussion}

To develop a rapid and easy-to-perform method for the determination of SEN and SENNOX in honey the effect of the quantity of sugar present in the sample was evaluated considering the separation efficiency $\left(\mathrm{N}=16\left(\mathrm{t}_{\mathrm{R}} / \mathrm{w}\right)^{2}\right)$ and the retention factor $\left(k=t_{r}-t_{0} / t_{0}\right)$. The lowest sample dilution was selected to optimize the LVI, and the maximum sample injection volume in the range of $20-100 \mu \mathrm{L}$ was selected with the aim of decrease the LOD and LOQ values. Finally, fast separation with the simple preparation of sample (simple dilution) and $\mathrm{pH}$ adjustment of sample were evaluated to improve the sensitivity in relation to the chromatographic signal. 


\subsection{Percentage of Sugar}

The sugar stock solution (70\% total sugar) was diluted to give $2 \%, 4 \%, 6 \%, 8 \%, 10 \%$ and $12 \%$ of sugar. SEN and SENNOX were added to each diluted solution to give a final concentration of $50 \mu \mathrm{g} \cdot \mathrm{kg}^{-1}$ for each standard. The volume of solution injected was $10 \mu \mathrm{L}$. In Figure 2 the values for the separation efficiency obtained for each injection show that an increase in the percentage of sugar in the mimetic solution increased the efficiency, with the best value being obtained with a final sugar content of $8 \%$. The sugar content also provided the highest retention factor for both analytes. Thus, this percentage of sugar was selected in the subsequent experiments.

\subsection{Optimization of Large Injection Volume}

Using the solution containing $8 \%$ of sugar, the next step was to evaluate the injection of volumes in the range of $20-100 \mu \mathrm{L}$. The values for the retention factor were calculated for each injected volume and showed a direct and linear correlation with an increase in both alkaloids (data not shown). Also, the value for $\mathrm{t}_{0}$ remained practically constant in all experiments. The injection volume selected for the subsequent analysis was therefore 100 $\mu \mathrm{L}$. A further increase in the volume injected would require the modification of the hardware.

\subsection{Time Required to Remove Sugars Present in the Samples}

In order to determine the time necessary to remove the sugars present in the matrix, and thereby avoid their caramelization in the ESI source, a diluted sample containing approximately $1 \%$ of sugars was injected. Figure 3 shows the effect of the use of the discharge valve on the increase in the separation efficiency and retention factor for the SEN standard. It was verified that it was possible to remove the sugar content before the sample reached the ESI source, at 3 min.

\subsection{Effects of Sample pH}

In the study to determine the effect of changing the sample matrix $\mathrm{pH}$, the sugar content (8\%) and the injection volume $(100 \mu \mathrm{L})$ were fixed.

In the chromatogram in Figure 3, (SEN1) represents the peak for the honey sample without pH adjustment (pH 6.43) and (SEN2) relates to the honey sample with the $\mathrm{pH}$ adjusted to 9.5. The pKa values for SEN and SENNOX are around 8 , and a higher $\mathrm{pH}$ value increases the interaction of analytes with the stationary phase and consequently the retention factor. The retention of the other sample components did not vary significantly, indicating that they are acid compounds.

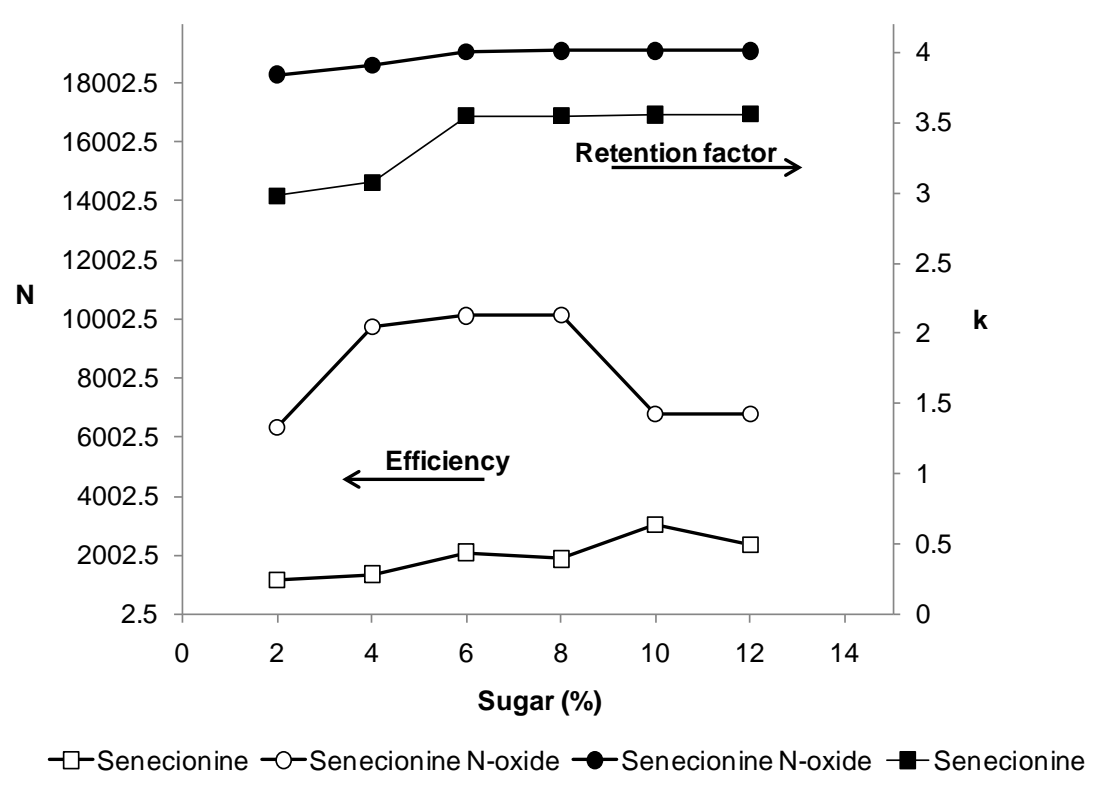

Figure 2. Effect of sample dilution on the separation efficiency and retention factor. 


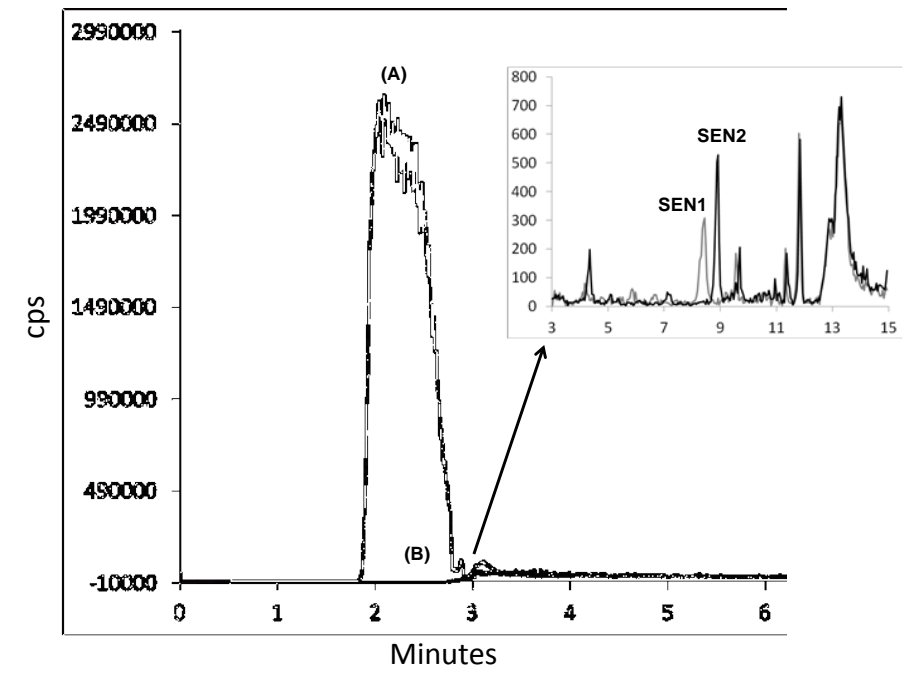

Figure 3. Chromatographic separation of honey (Sample C, Table 1). (A) analysis in negative mode for transition of $179-89 \mathrm{~m} / \mathrm{z}$ without use of sugar removal procedure and (B) analysis with use of discharge valve. Honey sample without adjustment at pH 6.4 (SEN1) and with adjustment at pH 9.5 (SEN2).

\subsection{Chromatographic Validation}

The linearity was tested with 10 concentration levels ranging from 200 to $2000 \mathrm{ng} \cdot \mathrm{L}^{-1}$. A sample of each concentration was prepared and injected in duplicate. The standard solutions prepared contained $8 \%$ of monosaccharides in order to mimic the matrix of honey samples. The linear regression equations were $y=9.7 \pm 0.2 \mathrm{x}+$ $1432.3 \pm 283.2$ and $\mathrm{y}=6.1 \pm 0.1 \mathrm{x}+770.4 \pm 192.7$ and the correlation coefficients were 0.9972 and 0.9966 for SEN and SENNOX, respectively.

The values obtained for the instrumental precision in relation to the retention time and peak area were 0.65 and 7.1\% RSD, respectively $(n=5)$. The RSD values for the repeatability (intra-day precision, $n=3$ ) in relation to the retention time and peak area were greater than $0.95 \%$ and $9.7 \%$, respectively. The Limits Of Detection (LOD) of the method for the determination of senecionine and senecionine $\mathrm{N}$-oxide under the optimized conditions were $57 \pm 16 \mathrm{ng} \cdot \mathrm{kg}^{-1}$ and $59 \pm 18 \mathrm{ng} \cdot \mathrm{kg}^{-1}$ (signal to noise ratio of 3). The Limits Of Quantification (LOQ) were $188 \pm 12 \mathrm{ng} \cdot \mathrm{kg}^{-1}$ and $195 \pm 14 \mathrm{ng} \cdot \mathrm{kg}^{-1}$ (signal to noise ratio of 10). Senecionine and senecionine N-oxide recovery experiments were carried out and the accuracy of the method was verified by the recovery values of 123.0 and $83.4 \%$, with the addition of 4.8 and $8 \mu \mathrm{g} \cdot \mathrm{kg}^{-1}$ of each analyte, respectively.

\subsection{Sample Analysis}

SEN was quantified in both of the commercial floral honey samples (A and B; Table 1). The samples obtained directly from the beekeepers contained different levels of SEN while the presence of SENNOX was detected in only two samples (E and G). The first product of the biosynthesis of pyrrolizidine alkaloids is the N-oxide form [22], produced in honey through a reduction reaction mediated by the constituents present in the honey or during the production process. However, Sample F provided the most alarming result with $1071.3 \pm 64.8 \mu \mathrm{g} \cdot \mathrm{kg}^{-1} \mathrm{of}$ SEN, indicating that its consumption poses a serious risk to human health, considering that the limit established for this alkaloid is $1 \mu \mathrm{g} / \mathrm{day}$. The presence and quantity of these alkaloids in honey obtained directly from beekeepers thus needs to be monitored and controlled, since the consumption of even low quantities of contaminated honey could represent a health hazard and conflict with the recognized proprieties of this product as a functional food.

\section{Conclusion}

The method using LVI-HPLC-MS/MS showed good accuracy and precision in the determination of senecionine and senecionine $\mathrm{N}$-oxide in honey samples without the need for a laborious sample clean-up procedure, thus in- 
Table 1. Quantification of senecionine and senecionine N-oxide present in honey samples $\left(\mu \mathrm{g} \cdot \mathrm{kg}^{-1}\right)$.

\begin{tabular}{ccc}
\hline Sample & SEN $( \pm$ SD $)$ & SENNOX $( \pm$ SD $)$ \\
\hline $\mathrm{A}^{1}$ & $19.7 \pm 1.6$ & $<\mathrm{LOD}$ \\
$\mathrm{B}^{1}$ & $9.1 \pm 1.2$ & $<\mathrm{LOD}$ \\
$\mathrm{C}^{2}$ & $1.9 \pm 0.1$ & $<\mathrm{LOD}$ \\
$\mathrm{D}^{2}$ & $9.8 \pm 1.3$ & $<\mathrm{LOD}$ \\
$\mathrm{E}^{2}$ & $7.0 \pm 1.0$ & $16.9 \pm 2.1$ \\
$\mathrm{~F}^{2}$ & $1071.3 \pm 64.8$ & $<\mathrm{LOD}$ \\
$\mathrm{G}^{2}$ & $<\mathrm{LOQ}$ & $2.3 \pm 0.3$ \\
$\mathrm{H}^{2}$ & $<\mathrm{LOQ}$ & $<\mathrm{LOD}$ \\
\hline
\end{tabular}

${ }^{1}$ Commercial floral honey; ${ }^{2}$ Floral honey obtained directly from beekeepers.

creasing the throughput of the methodology. The results of the sample analysis demonstrated the importance of monitoring the levels of SEN and SENNOX in honey, since these compounds pose a serious risk to human health.

\section{Acknowledgements}

We acknowledge INCT catalise, Conselho Nacional de Desenvolvimento Científico e Tecnológico (CNPq), Fundação de Amparo à Pesquisa do Estado de Santa Catarina (FAPESC) and Coordenação de Aperfeiçoamento de Pessoal de Nível Superior (CAPES).

\section{References}

[1] Stegelmeier, B.L., Edgar, J.A., Colegate, S.M., Gardner, D.R., Schoch, T.K., Coulombe, R.A. and Molyneux, R.J. (1999) Pyrrolizidine Alkaloid Plants, Metabolism and Toxicity. Journal of Natural Toxins, 8, 95-116.

[2] Roeder, E. (2000) Soft Medicinal Plants in China Containing Pyrrolizidine Alkaloids. Pharmazie, 55, 711-726.

[3] Coulombe Jr., R.A. (2003) Pyrrolizidine Alkaloids in Foods. Advances in Food and Nutrition Research, 45, 61-99. http://dx.doi.org/10.1016/S1043-4526(03)45003-1

[4] Martinello, M., Cristofoli, C., Gallina, A. and Mutinelli, F. (2014) Easy and Rapid Method for the Quantitative Determination of Pyrrolizidine Alkaloids in Honey by Ultra Performance Liquid Chromatography-Mass Spectrometry: An Evaluation in Commercial Honey. Food Control, 37, 146-152. http://dx.doi.org/10.1016/j.foodcont.2013.09.037

[5] Ridker, P.M., Ohkuma, S., Mc Dermott, W.V., Trey, C. and Huxtable, R.J. (1985) Hepatic Venocclusive Disease Associated with the Consumption of Pyrrolizidine Containing Dietary Supplements. Gastroenterology, 88, 1050-1054.

[6] EFSA (2011) Scientific Opinion on Pyrrolizidine Alkaloids in Food and Feed. EFSA Panel on Contaminants in the Food Chain (CONTAM). European Food Safety Authority (EFSA), Parma, 134.

[7] Schoental, R., Head, M.A. and Peacock, P.R. (1954) Senecio Alkaloids; Primary Liver Tumours in Rats as a Result of Treatment with (1) a Mixture of Alkaloids from S. jacobaea Lin.; (2) Retrorsine; (3) Isatidine. British Journal of Cancer, 8, 458-465. http://dx.doi.org/10.1038/bjc.1954.49

[8] Schoental, R. and Magee, P.N. (1957) Chronic Liver Changes in Rats after a Single Dose of Lasiocarpine, a Pyrrolizidine (Senecio) Alkaloid. The Journal of Pathology and Bacteriology, 74, 305-319. http://dx.doi.org/10.1002/path.1700740208

[9] Mohabbat, O., Shafiq Younos, M., Merzad, A.A., Srivastava, R.N., Sediq, G. and Aram, G.N. (1976) An Outbreak of Hepatic Veno-Occlusive Disease in North-Western Afghanistan. The Lancet, 308, 269-271. http://dx.doi.org/10.1016/S0140-6736(76)90726-1

[10] Kumana, C.R., Ng, M., Lin, H.J., Ko, W., Wu, P.C. and Todd, D. (1983) Hepatic Veno-Occlusive Disease Due to Toxic Alkaloid in Herbal Tea. The Lancet, 322, 1360. http://dx.doi.org/10.1016/S0140-6736(83)91112-1

[11] Stillman, A.S., Huxtable, R., Consroe, P., Kohnen, P. and Smith, S. (1977) Hepatic Veno-Occlusive Disease Due to Pyrrolizidine (Senecio) Poisoning in Arizona. Gastroenterology, 73, 349-352. 
[12] Tandon, B.N., Tandon, H.D., Tandon, R.K., Narndranathan, M. and Joshi, Y.K. (1976) An Epidemic of Veno-Occlusive Disease of Liver in Central India. Lancet, 2, 271-272. http://dx.doi.org/10.1016/S0140-6736(76)90727-3

[13] Kempf, M., Wittig, M., Reinhard, A., Von der Ohe, K., Blacquière, T., Raezke, K.P., Michel, R., Schreier, P. and Beuerle, T. (2010) Pyrrolizidine Alkaloids in Honey: Comparison of Analytical Methods. Food Additives \& Contaminants: Part A, 28, 332-347. http://dx.doi.org/10.1080/19440049.2010.521772

[14] Dübecke, A., Beckh, G. and Lüllmann, C. (2011) Pyrrolizidine Alkaloids in Honey and Bee Pollen. Food Additives \& Contaminants: Part A, 28, 348-358. http://dx.doi.org/10.1080/19440049.2010.541594

[15] Lin, G., Zhou, K.-Y., Zhao, X.-G., Wang, Z.-T. and But, P.P.H. (1998) Determination of Hepatotoxic Pyrrolizidine Alkaloids by On-Line High Performance Liquid Chromatography Mass Spectrometry with an Electrospray Interface. Rapid Communications in Mass Spectrometry, 12, 1445-1456. http://dx.doi.org/10.1002/(SICI)1097-0231(19981030)12:20<1445::AID-RCM356>3.0.CO;2-G

[16] Liu, F., Wan, S.Y., Jiang, Z.J., Li, S.F., Ong, E.S. and Osorio, J.C. (2009) Determination of Pyrrolizidine Alkaloids in Comfrey by Liquid Chromatography-Electrospray Ionization Mass Spectrometry. Talanta, 80, 916-923. http://dx.doi.org/10.1016/j.talanta.2009.08.020

[17] Wuilloud, J.C.A., Gratz, S.L.R., Gamble, B.M. and Wolnik, K.A. (2004) Simultaneous Analysis of Hepatotoxic Pyrrolizidine Alkaloids and N-Oxides in Comfrey Root by LC-Ion Trap Mass Spectrometry. Analyst, 129, 150-156. http://dx.doi.org/10.1039/b311030c

[18] Gray, D.E., Porter, A., O’Neill, T., Harris, R.K. and Rottinghaus, G.E. (2004) A Rapid Cleanup Method for the Isolation and Concentration of Pyrrolizidine Alkaloids in Comfrey Root. Journal of AOAC International, 87, 1049-1057.

[19] Mroczek, T., Ndjoko-Ioset, K., Głowniak, K., Miętkiewicz-Capała, A. and Hostettmann, K. (2006) Investigation of Symphytum Cordatum Alkaloids by Liquid-Liquid Partitioning, Thin-Layer Chromatography and Liquid Chromatography-Ion-Trap Mass Spectrometry. Analytica Chimica Acta, 566, 157-166. http://dx.doi.org/10.1016/j.aca.2006.03.016

[20] Colegate, S.M., Edgar, J.A., Knill, A.M. and Lee, S.T. (2005) Solid-Phase Extraction and HPLC-MS Profiling of Pyrrolizidine Alkaloids and Their N-Oxides: A Case Study of Echium plantagineum. Phytochemical Analysis, 16, 108-119. http://dx.doi.org/10.1002/pca.828

[21] Betz, J.M., Eppley, R.M., Taylor, W.C. and Andrzejewski, D. (1994) Determination of Pyrrolizidine Alkaloids in Commercial Comfrey Products (Symphytum sp.). Journal of Pharmaceutical Sciences, 83, 649-653. http://dx.doi.org/10.1002/jps.2600830511

[22] Hartmann, T. and Toppel, G. (1987) Senecionine n-Oxide, the Primary Product of Pyrrolizidine Alkaloid Biosynthesis in Root Cultures of Senecio vulgaris. Phytochemistry, 26, 1639-1643. http://dx.doi.org/10.1016/S0031-9422(00)82261-X

[23] Crews, C., Startin, J.R. and Clarke, P.A. (1997) Determination of Pyrrolizidine Alkaloids in Honey from Selected Sites by Solid Phase Extraction and HPLC-MS. Food Additives \& Contaminants, 14, 419-428. http://dx.doi.org/10.1080/02652039709374547

[24] Sârbu, C., Naşcu-Briciu, R.D., Casoni, D., Kot-Wasik, A., Wasik, A. and Namieśnik, J. (2012) Chromatographic Lipophilicity Determination Using Large Volume Injections of the Solvents Non-Miscible with the Mobile Phase. Journal of Chromatography A, 1266, 53-60. http://dx.doi.org/10.1016/j.chroma.2012.10.007

[25] Berset, J.-D., Brenneisen, R. and Mathieu, C. (2010) Analysis of Llicit and Illicit Drugs in Waste, Surface and Lake Water Samples Using Large Volume Direct Injection High Performance Liquid Chromatography-Electrospray Tandem Mass Spectrometry (HPLC-MS/MS). Chemosphere, 81, 859-866. http://dx.doi.org/10.1016/j.chemosphere.2010.08.011

[26] Nagai, J., Nakamura, Y., Ohira, S.-I. and Toda, K. (2013) Investigation of Daily Variation of Atmospheric Nitrophenols by Means of Inline Preconcentration-HPLC/MS Analysis with Large Volume Injection. Bunseki Kagaku, 62, 775783. http://dx.doi.org/10.2116/bunsekikagaku.62.775

[27] Backe, W.J., Day, T.C. and Field, J.A. (2013) Zwitterionic, Cationic, and Anionic Fluorinated Chemicals in Aqueous Film Forming Foam Formulations and Groundwater from US Military Bases by Nonaqueous Large-Volume Injection HPLC-MS/MS. Environmental Science \& Technology, 47, 5226-5234. http://dx.doi.org/10.1021/es3034999 
Scientific Research Publishing (SCIRP) is one of the largest Open Access journal publishers. It is currently publishing more than 200 open access, online, peer-reviewed journals covering a wide range of academic disciplines. SCIRP serves the worldwide academic communities and contributes to the progress and application of science with its publication.

Other selected journals from SCIRP are listed as below. Submit your manuscript to us via either submit@scirp.org or Online Submission Portal.
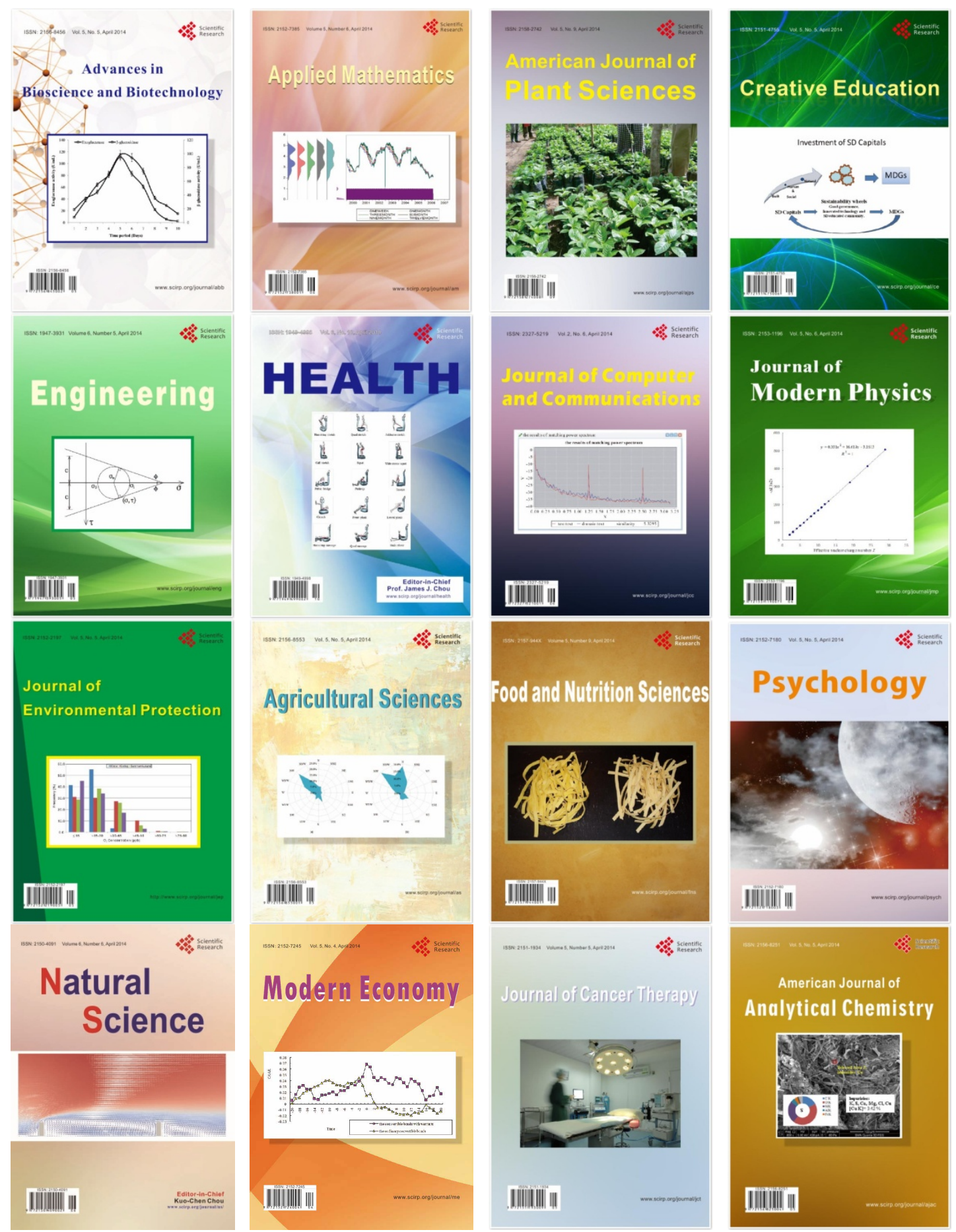